\title{
PONTOS DE CONTATO ENTRE O TRABALHO EM SALA DE LEITURA E A EDUCAÇÃO DIALÓGICA DE PAULO FREIRE
}

\section{POINTS OF CONTACT BETWEEN THE WORK IN THE READING ROOM AND THE DIALOGICAL EDUCATION OF PAULO FREIRE}

\author{
DIAS, Rosa Maria Noronha ${ }^{1}$
}

\section{RESUMO}

Apresento o conceito de leitura do mundo, criado por Paulo Freire e a relação deste com a leitura da palavra, destacando que por vezes a leitura do mundo que o aluno traz é desconsiderada pelo professor. Relaciono a leitura do mundo com a leitura da palavra a partir do meu trabalho como professora regente de Sala de Leitura da Secretaria Municipal de Educação do Rio de Janeiro. Faço um breve histórico sobre as Salas de Leitura e quais as atribuições do professor que nela trabalha. Afirmo a possibilidade de trabalhar com a Literatura nas Salas de Leitura dentro da perspectiva da educação dialógica freireana. Trago como pontos de contato entre o trabalho em Sala de Leitura e a educação dialógica, com suas aproximações e desafios, o trabalho com projetos, a práxis do professor, a valorização das diversas linguagens artísticas e a intencionalidade na escolha dos livros. Concluo reafirmando a atualidade do pensamento freireano.

PalaVRAS-ChAVe: Sala de leitura; Educação dialógica; Literatura; Leitura; Paulo Freire

\begin{abstract}
I present the concept of reading of the world, created by Paulo Freire and its relation with the reading of the word, emphasizing that sometimes the reading of the world that the student brings is disregarded by the teacher. I relate the reading of the world with the reading of the word based on my work as regent teacher of Reading Room of the Municipal Department of Education of Rio de Janeiro. I make a brief history about what the Reading Rooms are and what are the attributions of the teacher who works in it. I affirm the possibility of working with Literature in the Reading Rooms within the perspective of Freirean dialogic education. I bring as points of contact between the work in Reading Room and dialogic education, with its approaches and challenges, the work with projects, the praxis of the teacher, the valorization of the various artistic languages and the intentionality in the choice of books. I conclude by reaffirming the actuality of Freirean thinking.
\end{abstract}

KEY WORDS: Reading room; Dialogical education; Literature; Reading; Paulo Freire

\footnotetext{
${ }^{1}$ Mestranda do Programa de Pós-Graduação de Ensino em Educação Básica do Instituto de Aplicação Fernando Rodrigues da Silveira - PPGEB/CAp-UERJ; Professora da Rede Municipal de Educação do Rio de Janeiro. e-mail: rosmnd@bol.com.br
} 


\section{INTRODUÇÃO}

Se não amo o mundo, se não amo a vida, se não amo os homens, não me é possível o diálogo. (FREIRE, 1987, p. 45).

Antes de entrar na escola, o aluno traz em si uma vida prévia, construída a partir de suas vivências na realidade social onde está inserido, na interação com seus pares, na relação com o mundo que o cerca. Seus pertencimentos e suas apropriações. Este é um fato para o qual existem, em princípio, três possibilidades distintas de enfrentamento: ignora-se esta vivência, tomando o aluno como a antiga tábula rasa lockeana; desqualifica-se esta vivência, oferecendo ao aluno uma educação compensatória capaz de suprir suas necessidades escolares; aproveita-se esta vivência como parte integrante e fundamental do processo de aprendizagem, utilizando os saberes do aluno, somados aos saberes do professor no encontro dialógico entre eles.

A terceira possibilidade tem relação direta com o conceito de leitura do mundo apresentado por Paulo Freire. O aluno já estava no mundo antes de entrar na escola e, antes de tentar a leitura da palavra, já trazia consigo sua leitura do mundo, leitura que o identifica enquanto sujeito e que, segundo a perspectiva freireana, não pode ser deixada de lado, pois a palavra só será entendida em sua inteireza a partir do olhar de quem a lê.

Refiro-me a que a leitura do mundo precede sempre a leitura da palavra e a leitura desta implica a continuidade da leitura daquele. (...) Movimento em que a palavra dita flui do mundo mesmo através da leitura que dele fazemos. De alguma maneira, porém, podemos ir mais longe e dizer que a leitura da palavra não é apenas precedida pela leitura do mundo, mas por uma certa forma de "escrevê-lo" ou de "reescrevê-lo", quer dizer, de transformá-lo através de nossa prática consciente (FREIRE, 1989, p.13).

Freire vê no ato de alfabetizar mais do que um juntar de letras e sílabas e, no ato de ler, mais do que o treino de uma habilidade. A leitura da palavra na escola, segundo a perspectiva freireana, é uma ação política carregada de significados, desde a escolha do livro a ser lido até os desdobramentos compartilhados entre professor e alunos após a leitura. Como tornar este processo - nas palavras de Paulo Freire - libertador? Tomo como ponto de partida minha prática como professora regente de Sala de Leitura da Secretaria Municipal de Educação do Rio de Janeiro. 


\section{As SALAS de LEITURA COMO ESPAÇO dE diÁLOgo}

Criadas em 1985, as Salas de Leitura das escolas municipais substituem os espaços de Multimeios e Bibliotecas escolares anteriores a esta data. Foi uma mudança que ressignificou e redimensionou as práticas de leitura desenvolvidas nestes espaços.

Em 1992, as Salas de Leitura foram organizadas em Salas de Leitura Polo e Salas de Leitura Satélites, divisão que se mantem até hoje. As Salas de Leitura Polo têm a função de irradiar, multiplicar e acompanhar as orientações de trabalho vindas da Gerência de Mídia-Educação para as Salas Satélites, e em 1996, foram definidas as atribuições do Professor Regente de Sala de Leitura e as diretrizes para a organização do trabalho (RIO DE JANEIRO, 2007). Em 31 de março de 2010, a Resolução SME 1072 atualizou a estrutura e o funcionamento das Salas de Leitura.

Art $1^{\circ}$ As Salas de Leitura da Rede Pública do Sistema Municipal de Ensino devem ser espaços voltados para a promoção da leitura literária, para a formação de leitores e para a realização de pesquisas escolares, funcionando como estruturas de suporte ao desenvolvimento de propostas pedagógicas da escola, inclusive 0 reforço escolar;

Parágrafo único. A promoção da leitura e a formação de leitores citadas no caput deste artigo devem considerar a necessidade do acesso ao livro de literatura, bem como a outros suportes textuais, tais como vídeos, softwares e demais materiais impressos, audiovisuais ou digitais, contemplando a diversidade de textos e formatos existentes.

Art. $2^{\circ}$ A proposta de trabalho das Salas de Leitura deverá integrar o Projeto Político Pedagógico da respectiva escola, sendo organizada de acordo com as diretrizes estabelecidas pela E/SUBE/CED - MídiaEducação (RIO DE JANEIRO, 2010, p. 1-2).

Atuo na Sala de Leitura de uma escola pública municipal no bairro de Irajá, no Rio de Janeiro. Faço atendimento semanal a turmas de Educação Infantil até o $5^{\circ}$ ano, como também atendo uma turma de EJA.

O professor regente de Sala de Leitura é o profissional responsável por planejar, executar, avaliar e dar suporte às ações relacionadas à leitura dentro da unidade escolar, ou seja, é quem articula o trabalho de promoção de leitura, atuando em consonância com o projeto pedagógico da escola (DIAS, 2017, p.2). 
Ainda que a escola seja, em muitas situações, lugar de exclusão e opressão, também pode ser espaço privilegiado para o encontro entre o leitor e o livro. Nelly Novaes Coelho, no livro Literatura Infantil, afirma que os estudos literários podem ser realizados no contexto escolar com maior excelência do que em outros espaços e que eles

estimulam o exercício da mente; a percepção do real em suas múltiplas significações; a consciência do eu em relação ao outro; a leitura do mundo em seus vários níveis e, principalmente, dinamizam o estudo e o conhecimento da língua, da expressão verbal significativa e consciente - condição sine qua non para a plena liberdade do ser (COELHO, 2000, p.16. grifos nossos).

Ou seja, a leitura da palavra, como afirma Freire, deve ser um constante ir e vir entre o que está escrito no livro e os sentidos e significados que são despertos no leitor. Longe de ser uma atividade passiva de receber conhecimentos, ideias e histórias, a leitura da palavra precisa promover a inquietação que torna o leitor coautor da obra lida ou, como afirma Reyes (2013, s/p), "em diálogo permanente com o dado e com o que cada pessoa tem para dizer."

Retorno à pergunta feita anteriormente - sobre como o exercício da leitura da palavra na escola pode ser um processo de libertação - e buscarei desenvolver uma tentativa de resposta, discutindo os pontos de contato entre o trabalho a ser realizado numa Sala de Leitura e o conceito freireano de Educação Dialógica. Apresentarei como pontos de contato o trabalho com projetos, a práxis do professor, a valorização das diversas linguagens artísticas e a intencionalidade na escolha dos livros.

A educação dialógica se estabelece a partir do diálogo entre o professor e seus alunos. Não é a educação que se baseia na concepção bancária, conceito apresentado por Freire (1987) em $A$ pedagogia do oprimido, onde o professor serve apenas como um instrumento de dominação sobre o aluno, depositando sobre este os conteúdos que precisa interiorizar para continuar reproduzindo as desigualdades e injustiças que existem em nossa sociedade. Este professor-bancário não acredita na capacidade de seu aluno em dialogar, em ter algo a dizer, em seu poder de criação e de transformação. O professor e a escola na qual foi formado e que o mantém ignorante de sua própria ignorância não têm fé no aluno. $E$ a fé, a confiança em que o diálogo pode existir são condições primeiras para que ele se estabeleça.

O diálogo, como encontro dos homens para a tarefa comum de saber agir, se rompe, se seus polos (ou um deles) perdem a humildade.

Como posso dialogar se alieno a ignorância, isto é, se a vejo sempre no outro, nunca em mim? 
Como posso dialogar se me admito como um homem diferente, virtuoso por herança, diante dos outros, meros "isto", em quem não reconheço outros eu?

Como posso dialogar se me sinto participante de um "gueto" de homens puros, donos da verdade e do saber, para quem todos os que estão fora são "essa gente", ou são "nativos inferiores"?

(...) Não há também, diálogo, se não há uma intensa fé nos homens. (...) Fé na sua vocação de ser mais, que não é privilégio de alguns eleitos, mas direito dos homens (FREIRE, 1989, p. 46).

Ao promover projetos de leitura na escola, ao tornar acessível a herança cultural que temos através da Literatura e de outras expressões de arte, ao buscar junto aos alunos o que lhes afeta no encontro com os livros, creio que o professor de Sala de Leitura ocupa um lugar diferenciado no contexto escolar, menos preocupado com notas e conteúdos e mais disposto a ouvir o aluno e estabelecer com ele uma troca genuína, uma relação dialógica. Com certeza, esta é uma posição privilegiada e não há aqui a ingenuidade de crer nela completamente, pois este professor também foi formado pela escola que é espaço de disputas e contradições e que formou todos os outros professores. Para libertar-se - utilizando o conceito freireano - precisa estar em constante autoavaliação.

Ainda assim, como exercício de reflexão, relacionarei os pontos de contato observados entre o trabalho com a Literatura nas Salas de Leitura e a educação dialógica freireana.

\section{O TRABALHO COM PROJETOS}

O trabalho com projetos é a metodologia recomendada pela Secretaria Municipal de Educação - SME: "o desenvolvimento de Projetos de Trabalho constituise no principal eixo da metodologia, favorecendo a construção de práticas intertextuais e interdisciplinares" (RIO DE JANEIRO, 2007, p.21). Como afirmam Hernandez e Ventura (1998), o tema para um projeto pode ser escolhido a partir de um fato da atualidade, de um problema que tenha despertado o interesse da turma, de um conteúdo do currículo ou a partir de alguma observação do professor.

Penso que há muitas semelhanças entre o desenvolvimento de projetos de trabalho e de temas geradores, ainda que não sejam exatamente o mesmo recurso pedagógico. No entanto, creio que a aproximação entre estes seja a possibilidade de dar voz aos agentes da ação educativa, quer sejam os alunos e o professor. Os projetos e os temas geradores deixam de lado conteúdos alheios aos interesses do grupo e vão ao encontro do desenvolvimento de um assunto, de uma necessidade, de um problema que tenham eco entre aquelas pessoas. 
Enquanto na prática "bancária" da educação, anti-dialógica por essência, por isto, não comunicativa, o educador deposita no educando o conteúdo programático da educação, que ele mesmo elabora ou elaboram para ele, na prática problematizadora, dialógica por excelência, esse conteúdo, que jamais é "depositado", se organiza e se constitui na visão do mundo dos educandos, em que se encontram seus "temas geradores" (FREIRE, 1989, p.58).

No fazer da Sala de Leitura, trabalhar com projetos é mais do que saltar de data comemorativa em data comemorativa, de uma atividade isolada para outra, sem levar em consideração uma proposta de trabalho que promova repercussões, desdobramentos e aprofundamentos de um tema de interesse do grupo, sob a luz da Literatura.

\section{A PRÁXIS DO PROFESSOR}

Paulo Freire, ao apresentar o educador que deposita conteúdos em seus alunos, numa relação hierarquizada e alienante para ambos, defende que a ruptura com esta prática é justamente a inversão deste modelo, isto é, a ação pedagógica e libertadora deve se fazer na troca, no diálogo, na comunhão. "Ninguém educa ninguém, ninguém educa a si mesmo, os homens se educam entre si, mediatizados pelo mundo", afirma Freire (1989, p. 39). A aceitação dos saberes do aluno, a humildade em ouvi-los e buscar compreendê-los, compreensão que será feita pelo professor a partir de seus próprios saberes, pode levar a um encontro verdadeiro, um encontro de mundos que podem criar intercessões e crescimentos mútuos.

O texto literário pode ser o grande agente agregador, oferecendo terreno para o encontro entre o educador e o educando, em situações de leitura compartilhada. Segundo Bajour (2012, p. 26), " os textos literários nos tocam e nos questionam acerca de nossas visões sobre o mundo e nos convidam a perguntarmo-nos como viveríamos o que está representado nas ficções". Qual o trabalho do professor de Sala de Leitura com a palavra escrita? Que oportunidades ele pode oferecer ou negar? Onde está a mudança em comunhão proposta por Freire? Ler para os alunos uma história e depois entregar a eles um desenho xerocado da personagem principal para ser pintado esvazia a força do texto literário? Ou ainda:

As práticas de leitura literária mais habituais na escola ainda são bastante "monológicas", na medida em que os alunos aguardam que o professor faça sua leitura e o grau de participação dos leitores fica reduzido a uma escuta muitas vezes passiva ou excessivamente pautada por sentidos sugeridos de antemão (BAJOUR, 2012, p. 62). 


\title{
A VALORIZAÇÃO DAS DIVERSAS LINGUAGENS ARTÍSTICAS
}

No livro "A importância do ato de ler", Paulo Freire defende a existência de bibliotecas populares em consonância com a proposta de intercambiamento da leitura de mundo e da leitura da palavra.

\begin{abstract}
Contra tudo isso se coloca a posição critico-democrática da biblioteca popular. Da mesma maneira como, deste ponto de vista, a alfabetização de adultos e a pós-alfabetização implicam esforços no sentido de uma correta compreensão do que é a palavra escrita, a linguagem, as suas relações com o contexto de quem fala e de quem lê e escreve, compreensão portanto da relação entre "leitura" do mundo e leitura da palavra, a biblioteca popular, como centro cultural e não como um depósito silencioso de livros, é vista como fator fundamental para o aperfeiçoamento e a intensificação de uma forma correta de ler o texto em relação com o contexto. Daí a necessidade que tem uma biblioteca popular centrada nesta linha se estimular a criação de horas de trabalho em grupo, em que se façam verdadeiros seminários de leitura, ora buscando o adentramento crítico no texto, procurando apreender a sua significação mais profunda, ora propondo aos leitores uma experiência estética, de que a linguagem popular é intensamente rica (FREIRE, 1989, p. 20).
\end{abstract}

Nestas bibliotecas, que guardam grande semelhança com a proposta das Salas de Leituras escolares, há espaço para a leitura crítica do texto literário e há espaço também para as manifestações culturais e a expressão de outras linguagens artísticas. Estas últimas sempre devem ser apresentadas quando tiverem um valor em si, não como espetacularização do ato de ler.

\section{A INTENCIONALIDADE NA ESCOLHA DOS LIVROS}

"Não se pode educar ou formar leitores a partir de uma técnica neutra, independente das relações sociais e do mundo dos afetos", afirma Goldin (2012, p. 41).

Paulo Freire defende o ato de ensinar como um ato ideológico. Um ato que não permite a falsa crença na neutralidade do ofício do professor. Provoca os professores a escolherem. A escolherem que relação estabelecer com seus alunos, uma relação reprodutora e cerceadora ou uma relação dialógica que suscite a mudança de ambos, a libertação de ambos, nos dizeres de Freire. Educar é tomar partido. Não há a possibilidade de não escolher. Escolhe-se mesmo quando, ingenuamente, pensa-se não estar escolhendo. 
Com os livros lidos aos alunos, repete-se a mesma dinâmica. A escolha do que ler para eles também não é inocente, ainda que por vezes o professor da Sala de Leitura não tenha consciência disso. Existem livros rasos, superficiais, que veiculam estereótipos e preconceitos, da mesma forma que há livros ricos, fortes, polissêmicos. Estes últimos são livros que dialogam com o leitor e o fazem ir além, para construir outros sentidos e vislumbrar novos mundos. Neste processo, 0 professor tem papel fundamental, ao fazer a mediação entre o aluno/leitor e o livro. Bajour (2012) reafirma o caráter ideológico da escolha dos livros a serem apresentados:

É fundamentalmente uma atitude ideológica que parte do compromisso com os leitores e com os textos e do lugar conferido a todos aqueles que participam da experiência de ler. Por isso, a escuta como prática pedagógica e cultural, que combina a exigência com a confiança na capacidade de todos os leitores, pode ter resultados transformadores em contextos marcados por processos de exclusão econômica e social e por diversas formas de autoritarismo (BAJOUR, 2012, p. 45).

\section{CONSIDERAÇÕES FINAIS}

Trazer a educação dialógica para dentro da Sala de Leitura é uma ação que exige questionamentos e reflexões constantes. Ainda que existam aproximações, pontos de contato entre elas, como foi o objetivo deste artigo discutir, este reconhecimento não assegura uma prática sem conflitos ou inconsistências.

A metodologia de trabalho com projetos valoriza o conhecimento orientado pelo interesse do grupo de alunos e do professor. É a busca coletiva de saber mais sobre temas que façam sentido e colaborem na formação daqueles agentes da ação educativa. Mas, às vezes tecemos uma colcha de retalhos de histórias e atividades pós-leitura que não colaboram na construção de um aluno/leitor sensível e crítico.

A práxis do professor de Sala de Leitura precisa abrir espaço para o diálogo, mais especificamente para o diálogo do aluno com o livro e, a partir daí, do aluno com o mundo. Desvendar com os alunos os ditos, as entrelinhas, suportar os silêncios, as confusões, deixar que os alunos falem. Este é um processo longo, de conquista, erros e acertos. Mais tentador para o professor é tornar bancária a leitura literária, conduzindo autocraticamente os alunos pelos caminhos que já conhece e que lhe são confortáveis.

A dialogia no trabalho em Sala de Leitura pode ser percebida, inclusive, na possibilidade de abrir espaço para outras linguagens artísticas que não unicamente a Literatura. É a humildade de agregar variadas formas de expressão estéticas que conversem com o texto literário e que possam auxiliar na intermediação leitor/livro. 
DOI: $10.12957 /$ e-mosaicos.2017.30793

O reconhecimento de que este encontro pode se dar de várias formas. Sem perder de vista - é importante lembrar - que a prioridade neste contexto é valorizar o texto literário, não se sobrepor a ele.

A intencionalidade na escolha dos livros sempre acontece, de uma forma ou de outra. Seja quando o professor de Sala de Leitura busca instrumentalizar seus alunos com livros que os ajudem a olharem para dentro, a olharem em volta e a se indignarem com as dores do mundo, seja quando este professor não tem consciência de seu papel político e oferece aos seus alunos livros que não estimularão a criticidade e que apenas perpetuam o modelo opressor-oprimido. A consciência desta escolha demanda um desejo e um trabalho interno do professor.

Ou seja, é constante a necessidade de autocrítica, de reconhecimento do binômio opressor-oprimido que ainda trazemos em nós. $O$ diálogo freireano tem como característica principal o compromisso com a transformação, a inquietação, a incompletude. "O diálogo freireano prioriza a pergunta que faz pensar, que nos coloca em dúvida e não a resposta pronta, espontânea, "neutra", sem reflexão", como afirma Freire (2015, p. 295) no texto A leitura do mundo e a leitura da palavra em Paulo Freire.

É o convite ao risco, ao desmontar de certezas, à troca, à comunhão, à libertação das opressões. Convite feito por Paulo Freire há algumas décadas aos educadores/educandos e que permanece atual diante das situações de violência e desumanidade que vivenciamos nas diversas esferas da vida social, inclusive presenciando ataques à pessoa e à obra de Paulo Freire. Porque suas palavras ainda incomodam, denunciam e expõem o não-dito. Ainda trazem em si a marca da ousadia.

\section{REFERÊNCIAS BIBLIOGRÁFICAS}

BAJOUR, C. Ouvir nas entrelinhas: o valor da escuta nas práticas de leitura. São Paulo: Pulo do Gato, 2012.

COELHO, N. N. Literatura infantil. São Paulo: Moderna, 2000.

DIAS, R. M. N. Sala de Leitura - que sala é essa? Cadernos da Educação Básica, Rio de Janeiro, vol. 1, n. 3, p. 51 -58, jan., 2017. Disponível em http://cp2.g12.br/ojs/index.php/cadernos/article/view/979/706 . Acesso em: 13 de outubro de 2017.

GOLDIN, D. Os dias e os livros. divagações sobre a hospitalidade da leitura. São Paulo: Pulo do Gato, 2012.

FREIRE, A. M. A. A leitura do mundo e a leitura da palavra em Paulo Freire. Cadernos Cedes, Campinas, v. 35, n. 96, p. 291-298, maio-ago., 2015. Disponível em 
DOI: $10.12957 /$ e-mosaicos.2017.30793

http://www.scielo.br/pdf/ccedes/v35n96/1678-7110-ccedes-35-96-00291.pdf .

Acesso em: 13 de outubro de 2017.

FREIRE, Paulo. A importância do ato de ler. São Paulo: Autores Associados: Cortez, 1989.

. A pedagogia da autonomia. São Paulo: Paz e Terra, 1996.

. A pedagogia do oprimido. Rio de Janeiro: Paz e Terra, 1987.

HERNANDEZ, F. e VENTURA, M. A organização do currículo por projetos de trabalho. Porto Alegre: Artmed, 1998.

REYES, Y. Mundos possíveis. Explorar a fantasia... para inventar a realidade. Revista Emília, abril de 2013. Disponível em:

http://www.revistaemilia.com.br/mostra.php?id=299 . Acesso em: 31 de agosto de 2016.

RIO DE JANEIRO. Secretaria Municipal de Educação. Multieducação: Sala de Leitura. 2.ed. Rio de Janeiro, 2007.

. Secretaria Municipal de Educação. Resolução SME nº 1072, de 31

de março de 2010. Dispõe sobre a estrutura e o funcionamento das Salas de Leitura nas Unidades Escolares da Rede Pública do Sistema Municipal de Ensino do Rio de Janeiro e dá outras providências. Disponível em:

https://pt.scribd.com/document/333665922/Resolua-A\%C6\%92o-de-Sala-de-LeituraSme-Na\%C2\%BA-1072 . Acesso em: 10 de outubro de 2017.

Recebido em 14 de outubro de 2017. Aceito em 29 de outubro de 2017. 